\title{
Mouse-adapted H9N2 avian influenza virus causes systemic infection in mice
}

\author{
Zhe Hu${ }^{1 \dagger}$, Yiran Zhang ${ }^{1,2 \dagger}$, Zhen Wang ${ }^{1 \dagger}$, Jingjing Wang ${ }^{1}$, Qi Tong ${ }^{1}$, Mingyang Wang ${ }^{1}$, Honglei Sun ${ }^{1}$, Juan Pu', \\ Changqing Liu², Jinhua Liu ${ }^{1 *}$ and Yipeng Sun ${ }^{1 *}$
}

\begin{abstract}
Background: H9N2 influenza viruses continuously circulate in multiple avian species and are repeatedly transmitted to humans, posing a significant threat to public health. To investigate the adaptation ability of H9N2 avian influenza viruses (AIVs) to mammals and the mutations related to the host switch events, we serially passaged in mice two H9N2 viruses of different HA lineages - A/Quail/Hong Kong/G1/97 (G1) of the G1-like lineage and A/chicken/ Shandong/ZB/2007 (ZB) of the BJ/94-like lineage — and generated two mouse-adapted H9N2 viruses (G1-MA and ZB-MA) that possessed significantly higher virulence than the wide-type viruses.
\end{abstract}

Finding: ZB-MA replicated systemically in mice. Genomic sequence alignment revealed 10 amino acid mutations coded by 4 different gene segments (PB2, PA, HA, and M) in G1-MA compared with the G1 virus and 23 amino acid mutations in 5 gene segments (PB1, PA, HA, M, and NS) in ZB-MA compared to ZB virus, indicating that the mutations in the polymerase, $\mathrm{HA}, \mathrm{M}$, and NS genes play critical roles in the adaptation of H9N2 AIVs to mammals, especially, the mutations of M1-Q198H and M1-A239T were shared in G1-MA and ZB-MA viruses. Additionally, several substitutions showed a higher frequency in human influenza viruses compared with avian viruses.

Conclusions: Different lineages of H9N2 could adapt well in mice and some viruses could gain the ability to replicate systemically and become neurovirulent. Thus, it is essential to pay attention to the mammalian adaptive evolution of the H9N2 virus.

Keywords: H9N2 avian influenza virus, Adaption, Mutation, Mice

\section{Main text}

H9N2 avian influenza viruses (AIVs) have been circulating in multiple avian species and are repeatedly transmitted to mammals, including humans and pigs [1-3]. In addition, since H9N2 viruses cause mild infections in humans, causing a typical human flu-like illness that can easily go unnoticed, they have the opportunity to adapt to humans. Recent evidence suggested that H9N2 viruses isolated from China after 2010 have displayed higher virulence to chicken and mice, and some naturally isolated H9N2 viruses tested were transmissible in ferrets by respiratory droplets [4]. In 2013, a novel reassortant H7N9 virus carrying six internal genes from

\footnotetext{
*Correspondence: ljh@cau.edu.cn; sypcau@163.com

†Zhe Hu, Yiran Zhang and Zhen Wang contributed equally to this work.

${ }^{1}$ Key Laboratory of Animal Epidemiology of the Ministry of Agriculture, College of Veterinary Medicine, China Agricultural University, Beijing 100193, China

Full list of author information is available at the end of the article
}

H9N2 AIV caused serious outbreaks in humans in China [5-7]. In fact, the susceptibility of H7N9 to humans is thought to be partly due to the adaptability of H9N2 to mammals [8-10]. Thus, investigating the adaptation of H9N2 to mammals will be helpful for the prevention of avian influenza virus interspecies transmission. Phylogenetic analysis indicated that the HA genes of H9N2 viruses in China mainly fall into two lineages, the BJ/94like and G1-like [1,3]. Human infections with these two lineages were often observed [11]. However, research on the adaptive genetic basis of G1-like and BJ/94-like H9N2 influenza viruses to mammals is still scarce. Mice are ideal animal models for investigating the pathogenic mechanisms and host range determinants of influenza virus, and they can be used to generate mouse-adapted variants by serial lung-to-lung passages $[12,13]$. Some studies showed that BJ/94-like viruses could adapt well to mice $[12,14]$. However, there has been no research on the adaptation of G1-like H9N2 viruses to mice. In

(c) The Author(s). 2019 Open Access This article is distributed under the terms of the Creative Commons Attribution 4.0 International License (http://creativecommons.org/licenses/by/4.0/), which permits unrestricted use, distribution, and 

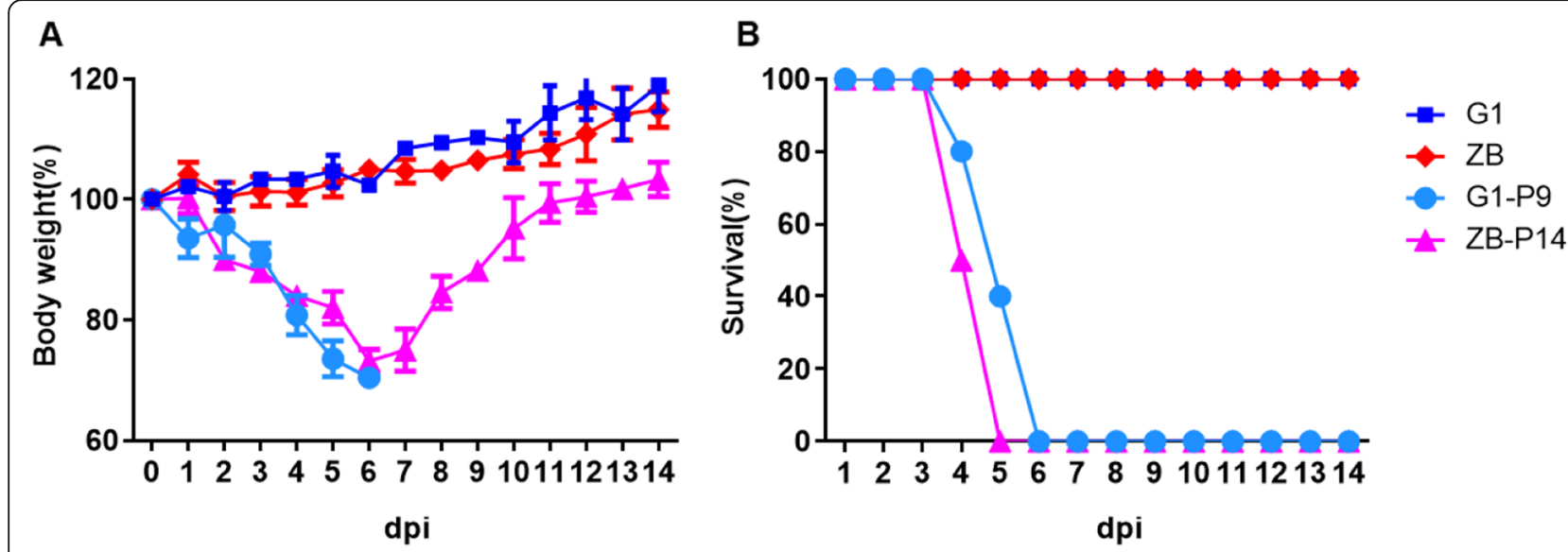

Fig. 1 Virulence of G-P9, ZB-P14, and wild-type viruses in mice. Groups of five six-week-old BALB/C mice were inoculated intranasally with G1-P9, ZB-P14, or wild-type H9N2 viruses. Body weight (a) and survival (b) were monitored daily for 14d

the present study, we generated two mouse-adapted H9N2 viruses by serial lung passages and studied the pathogenicity and molecular variation of the two mouse adaptive viruses. We found that the G1-like H9N2 strain adapted more rapidly than the $\mathrm{BJ} / 94$-like virus and that ZB-MA virus gained the ability to replicate systemically and became neurovirulent. These results provide a theoretical basis to evaluate the potential threat of $\mathrm{H} 9 \mathrm{~N} 2$ to public health.

To generate mouse-adapted viruses, the G1 strain and ZB strains were serially passaged in six-week-old female mouse lungs, beginning with an intranasal inoculation of $10^{5} \mathrm{pfu}$ of virus per mouse. At 3 days post-inoculation (dpi), mice were killed, their lungs were harvested and homogenized, and $50 \mu \mathrm{l}$ of supernatant from the centrifuged homogenate were used as inoculum for the next passage. Survival and clinical symptoms of infected animals were recorded after each passage. The wildtype $\mathrm{G} 1$ and $\mathrm{ZB}$ were almost avirulent in mice, and the weight loss of the infected mice became more and more serious with the increase in the number of generations of the virus. After nine passages, all of the mice inoculated in the G1 virus died at 6 dpi (Fig.1), whereas after 14 passages of the $\mathrm{ZB}$ virus all inoculated mice died at 5 dpi.

To further study the pathogenicity of mouse adaptive strains to mammals, we performed plaque purification and genome sequencing to the acquired monoclonal strains of G1 P9 and ZB P14 (named G1-MA and ZBMA respectively). Next, we compared the virulence of the generated mouse-adapted variant with that of the wild-type strains. The $M D_{50}$ value showed that G1-MA was $>10^{2.15}$-fold more virulent than G1 virus and ZBMA was $>10^{2.75}$-fold more virulent than $\mathrm{ZB}$ virus (Table 1). All of the mice infected with $10^{5}$ pfu of G1MA or ZB-MA exhibited severe clinical signs of disease, including decreased activity, huddling, hunched posture, and ruffled fur. Mice in the G1-MA group began to die at 5 dpi (Fig. $2 \mathrm{a}$ and b), and mice in the ZB-MA group began to die at $3 \mathrm{dpi}$ (Fig. $2 \mathrm{c}$ and d). In contrast, the parental mice infected with $10^{5}$ pfu of wild type virus displayed weight increase over a period of 14 days and no morbidity or mortality was observed. To determine whether the differences in virulence of the mouseadapted H9N2 and wild-type strains were due to a different ability to spread and replicate in the mouse organs, groups of three $\mathrm{BALB} / \mathrm{c}$ mice were killed at $3 \mathrm{dpi}$, and various organs, including the liver, spleen, lung, kidney, and brain, were harvested for virus detection and titration. G1-MA and ZB-MA replicated to significantly high levels in the lungs, reaching viral titers $10^{1.3}$-fold and $10^{2.0}$-fold higher than those of $\mathrm{G} 1$ virus and $\mathrm{ZB}$, respectively $(p<0.05)$. The ZB-MA virus was also detected in liver, spleen, lung, kidney and brain (Table 2 and Fig.2e), indicating that the ZB-MA virus had gained the ability to replicate in all of the tested organs (systematically), including the central nervous system. No infectious virus was detected in any organ other than the lung from any of the mice infected with any of the G1, G1$\mathrm{MA}$, and $\mathrm{ZB}$ viruses.

The pathogenesis of influenza A viruses is a polygenic trait and understanding the molecular mechanisms

Table 1 Virulence change of G1 and ZB virus during mouse adaption

\begin{tabular}{lll}
\hline Virus & $\begin{array}{l}\mathrm{MLD}_{50} \\
\left(\log _{10} \mathrm{EID}_{50} \mathrm{ml}^{-1}\right)\end{array}$ & $\begin{array}{l}\text { Change in } \mathrm{MLD} \\
\left(\log _{10} \text { decrease }\right)\end{array}$ \\
\hline G1 & $>6$ & $\mathrm{NA}^{\mathrm{a}}$ \\
ZB & $>6$ & $\mathrm{NA}$ \\
G1-MA & 3.85 & $>2.15$ \\
ZB-MA & 3.25 & $>2.75$ \\
\hline
\end{tabular}

${ }^{a}$ Not applicable 


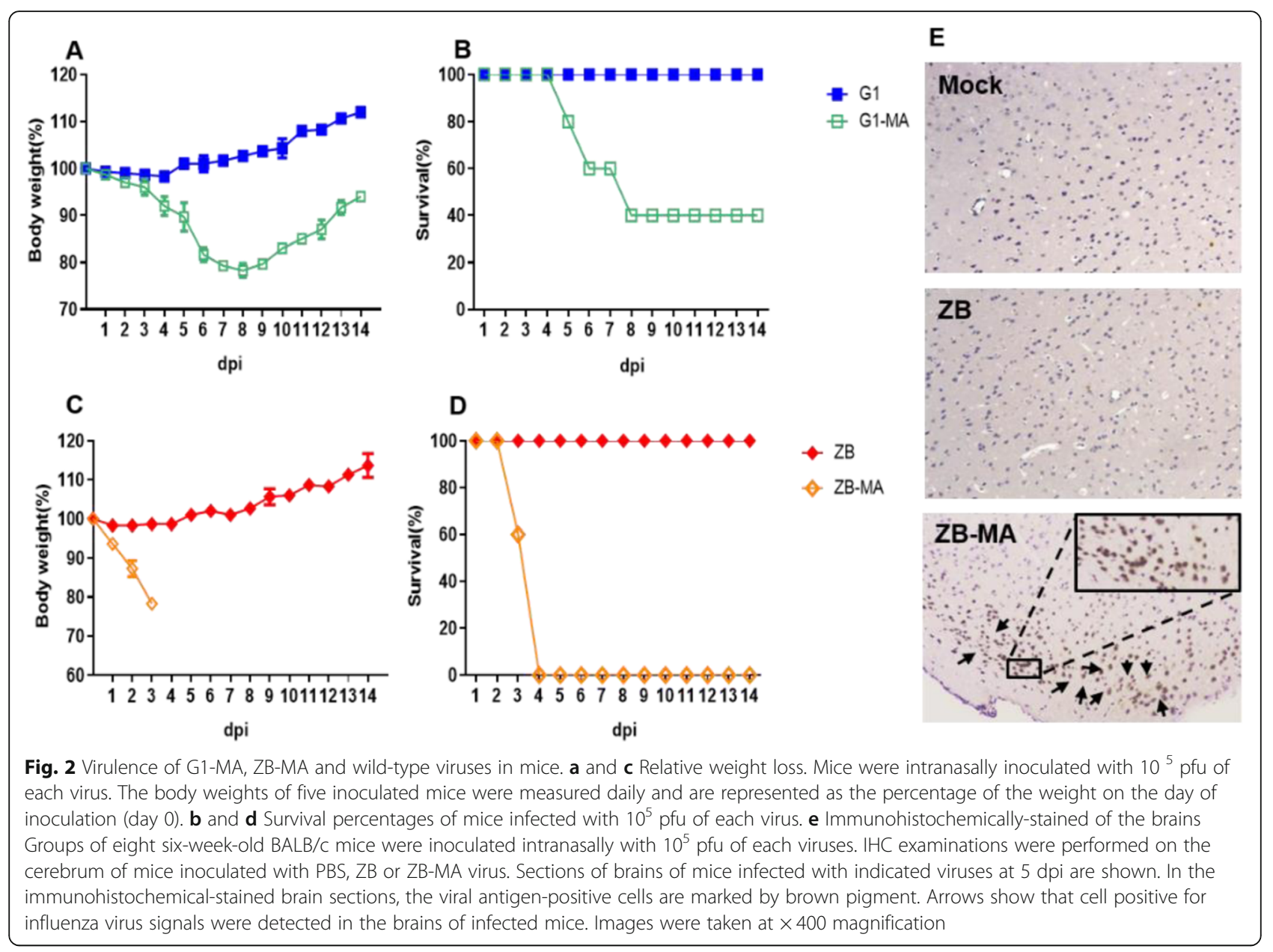

Table 2 Viral distribution of wild-type and mouse-adapted viruses in different tissues in mice

\begin{tabular}{llllll}
\hline Virus & \multicolumn{5}{l}{ Mean virus titer in sample $\left[\log _{10} \mathrm{TCID}_{50} \mathrm{ml}^{-1}\right] \pm \mathrm{SD}$} \\
\cline { 2 - 6 } & Lung & Liver & Spleen & Kidney & Brain \\
\hline G1 & $3 / 3^{\mathrm{a}}$ & $-\mathrm{b}$ & - & - & - \\
& $(5.6 \pm 0.6)$ & & & & \\
G1-MA & $3 / 3$ & - & - & - & - \\
& $\left(6.9 \pm 0.3^{\mathrm{C}}\right)$ & & & & \\
ZB & $3 / 3$ & - & - & - & - \\
& $(5.0 \pm 0.1)$ & & & & \\
ZB-MA & $3 / 3$ & $2 / 3$ & $3 / 3$ & $2 / 3$ & $3 / 3$ \\
& $\left(7.0 \pm 0.1^{\mathrm{d}}\right)$ & $(2.6 \pm 0.1)$ & $(3.3 \pm 0.1)$ & $(3.1 \pm 0.2)$ & $(3.7 \pm 0.2)$
\end{tabular}

${ }^{\mathrm{a} N o}$. of infected mice/total no. of mice

${ }^{b}$ No virus was isolated from the sample

${ }^{\text {C}}$ The lung titers in the G1-MA group were significantly higher than those in the $\mathrm{G} 1$ group $(p<0.05)$

${ }^{\mathrm{d}}$ The lung titers in the ZB-MA group were significantly higher than those in the ZB group $(p<0.05)$ important to the host range and pathogenesis is critical for the prevention and treatment of influenza A virus infections [15]. To identify the molecular basis for the enhanced virulence acquired by H9N2 viruses during adaption, the genomes of the wild-type and mouseadapted viruses were sequenced. The comparison of the full coding sequences between mice adapted strains and their corresponding wild-type strains revealed 10 and 23 amino acid mutations in G1-MA and ZB-MA, respectively (Table 3 and Table 4). M1-Q198H and M1-A239T were found in both G1-MA and ZB-MA viruses and 97\% of human H3N2 influenza viruses possessed M1$239 \mathrm{~T}$. Except for M1-239 T, there were 9 additional substitutions in ZB-MA strain also presented more frequently in human $\mathrm{H} 9 \mathrm{~N} 2, \mathrm{pH} 1 \mathrm{~N} 1$ or human $\mathrm{H} 3 \mathrm{~N} 2$ influenza viruses, including PA-S489C, NA-V377I, M1S157A, M1-H158Q, M1-Q222H, M2-H10L, M2-E16G, M2-I27V, and M2-V32I. Additionally, PA-T97I, PAE349K and HA-I204M have also been detected in miceadapted strains previously [16-18]. These results indicated the related substitutions might be important for the mammalian adaptation of H9N2 influenza viruses. In order to analyze the possible molecular basis of these mutations 
Table 3 Amino acid differences between the wild-type strain G1 and the mouse-adapted strain G1-MA

\begin{tabular}{|c|c|c|c|c|c|c|c|}
\hline Proteins & AA site & G1 & G1-MA & Avian H9N2 & Human H9N2 & $\mathrm{pH} 1 \mathrm{~N} 1$ & Human $\mathrm{H} 3 \mathrm{~N} 2$ \\
\hline \multirow[t]{3}{*}{ PB2 } & $590^{\mathrm{a}}$ & $S$ & $\mathrm{R}$ & G (97.5\%) & S (100\%) & S (85\%) & $\mathrm{T}(47 \%)$ \\
\hline & & & & & & & S (45\%) \\
\hline & & & & S (2.5\%) & & $G(15 \%)$ & G (8\%) \\
\hline \multirow[t]{2}{*}{ PA } & $349^{c}$ & E & K & $E(100 \%)$ & $E(100 \%)$ & $E(100 \%)$ & $E(100 \%)$ \\
\hline & 486 & I & M & I (100\%) & I (100\%) & I (100\%) & I (100\%) \\
\hline \multirow[t]{10}{*}{ HA } & $204(196)^{b c}$ & । & M & $\mathrm{T}(95 \%)$ & $\mathrm{T}(60 \%)$ & I & / \\
\hline & & & & K (4.2\%) & I (40\%) & & \\
\hline & & & & $A(0.6 \%)$ & & & \\
\hline & & & & I (0.2\%) & & & \\
\hline & 206 (198) & N & $\mathrm{T}$ & Т (95\%) & $\mathrm{T}(60 \%)$ & / & / \\
\hline & & & & A (4.2\%) & & & \\
\hline & & & & N (0.8\%) & N (40\%) & & \\
\hline & $271(263)$ & G & $E$ & E (99\%) & $E(60 \%)$ & / & / \\
\hline & & & & G (0.5\%) & & & \\
\hline & & & & V (0.5\%) & G (40\%) & & \\
\hline \multirow[t]{5}{*}{ M1 } & 198 & Q & $\mathrm{H}$ & Q (100\%) & Q (100\%) & Q (99\%) & Q (100\%) \\
\hline & & & & & & $H(1 \%)$ & \\
\hline & 239 & A & $\mathrm{T}$ & A (100\%) & A (100\%) & A (100\%) & ${\underline{\mathrm{T}(97 \%)^{\mathrm{d}}}}^{\mathrm{d}}$ \\
\hline & & & & & & & A (2\%) \\
\hline & & & & & & & V (1\%) \\
\hline \multirow[t]{11}{*}{ M2 } & 91 & C & $\mathrm{F}$ & F (99.8\%) & $F(100 \%)$ & $F(51 \%)$ & $F(100 \%)$ \\
\hline & & & & & & $\mathrm{T}(47 \%)$ & \\
\hline & & & & & & $V(1 \%)$ & \\
\hline & & & & $C(0.2 \%)$ & & L (1\%) & \\
\hline & 93 & । & $\mathrm{N}$ & N (99.5\%) & N (100\%) & N (89\%) & S (99\%) \\
\hline & & & & I (0.1\%) & & & \\
\hline & & & & $K(0.1 \%)$ & & & \\
\hline & & & & S (0.1\%) & & & \\
\hline & & & & $\mathrm{T}(0.1 \%)$ & & S (9\%) & \\
\hline & & & & & & D (1\%) & N (1\%) \\
\hline & & & & & & $\mathrm{T}(1 \%)$ & \\
\hline
\end{tabular}

${ }^{\mathrm{a}} \mathrm{H} 9$ numbering

${ }^{b} \mathrm{H} 3$ numbering is in parentheses

'The substitutions also occurred in mice-adapted influenza viruses in the previous studies

${ }^{\mathrm{d}}$ The substitution which presents more frequently in human influenza viruses than H9N2 AIVs was shown by bold and underline formats

leading to increased pathogenicity, we further analyzed the functional areas where these mutations are located (Fig. 3). In the G1-MA virus, HA-I204M and HA-N206 T occur in the receptor binding site and PB2-S509R is located in the overlapping regions of the NP and PB1 binding domains; M1-Q198H and M1-A239T reside in the RNP binding region. In the ZB-MA virus, the M1-E29V, M1-Q198H, M1-I219V, M1-Q222H, and M1-A239T mutations reside in the RNP binding region, M1-S157A and M1-H158Q mutations reside in RNA binding region; the M2-I27V, M2-V32I, and M2-H37R mutations occur in the ion channel.
Our results show that the G1 and ZB H9N2 viruses could evolve to be highly pathogenic for mice after serial passage in mouse lungs, and the adaptation of the H9N2 AIVs to mice involves multiple amino acid substitutions in viral polypeptides. Several substitutions were not detected in the mice-adapted strains previously and many of them showed higher frequency in human viruses than H9N2 AIVs, indicating their importance for mammalian adaptation. Previous studies reported that influenza viruses can cause not only respiratory diseases but also nervous system syndrome [19] and diseases of the nervous system could pose a serious threat to the host 
Table 4 Amino acid differences between the wild-type strain ZB and the mouse-adapted strain ZB-MA

\begin{tabular}{|c|c|c|c|c|c|c|c|}
\hline Proteins & AA site & ZB & ZB-MA & Avian H9N2 & Human H9N2 & $\mathrm{pH} 1 \mathrm{~N} 1$ & Human H3N2 \\
\hline \multirow[t]{2}{*}{ PB1 } & $141^{\mathrm{a}}$ & $T$ & $A$ & T (100\%) & $\mathrm{T}(100 \%)$ & $T(100 \%)$ & $\mathrm{T}(100 \%)$ \\
\hline & 708 & $P$ & L & $P(100 \%)$ & $P(100 \%)$ & $P(100 \%)$ & $P(100 \%)$ \\
\hline \multirow[t]{4}{*}{ PA } & $97^{c}$ & $\mathrm{~T}$ & 1 & T (100\%) & T (100\%) & T (99\%) & T (100\%) \\
\hline & & & & & & $N(1 \%)$ & \\
\hline & 489 & S & C & C (97\%) & $C(100 \%)^{d}$ & C (100\%) & C (100\%) \\
\hline & & & & $S(3 \%)$ & & & \\
\hline \multirow[t]{4}{*}{ HA } & $27(19)^{b}$ & S & L & S (100\%) & $S(100 \%)$ & / & / \\
\hline & $517(508)$ & E & G & E (99\%) & $E(100 \%)$ & / & / \\
\hline & & & & D (1\%) & & & \\
\hline & $556(544)$ & C & $\mathrm{R}$ & C (100\%) & C (100\%) & / & / \\
\hline \multirow[t]{3}{*}{ NA } & 377 & V & 1 & V (89\%) & V (44\%) & / & V (48\%) \\
\hline & & & & I (11\%) & $\underline{\text { I }(56 \%)}$ & & $\mathrm{T}(47 \%)$ \\
\hline & & & & & & & I (5\%) \\
\hline \multirow[t]{12}{*}{ M1 } & 29 & $\mathrm{E}$ & V & $E(100 \%)$ & $E(100 \%)$ & $E(100 \%)$ & $E(100 \%)$ \\
\hline & 119 & Y & $\mathrm{H}$ & $Y(100 \%)$ & Y (100\%) & $Y(100 \%)$ & $Y(100 \%)$ \\
\hline & 157 & S & A & A (89\%) & A (100\%) & $S(100 \%)$ & S (100\%) \\
\hline & & & & S (11\%) & & & \\
\hline & 158 & $\mathrm{H}$ & Q & Q (94\%) & $\mathrm{Q}(100 \%)$ & Q (100\%) & $\mathrm{Q}(100 \%)$ \\
\hline & & & & $H(6 \%)$ & & & \\
\hline & 198 & Q & $\mathrm{H}$ & Q (100\%) & Q (100\%) & $\begin{array}{l}\text { Q (99\%) } \\
\text { H (1\%) }\end{array}$ & Q (100\%) \\
\hline & 219 & I & v & V (87\%) & V (40\%) & I (100\%) & I (100\%) \\
\hline & & & & I (13\%) & I (60\%) & & \\
\hline & 222 & Q & $\mathrm{H}$ & H (88\%) & $\underline{\mathrm{H}(100 \%)}$ & $\underline{\mathrm{H}(100 \%)}$ & $\underline{\mathrm{H}(100 \%)}$ \\
\hline & & & & Q (12\%) & & & \\
\hline & 239 & A & T & A (100\%) & A (100\%) & A (100\%) & $\frac{\mathrm{T}(\mathbf{9 7 \%})}{\mathrm{A}(2 \%)}$ \\
\hline \multirow[t]{17}{*}{ M2 } & 10 & $\mathrm{H}$ & L & L (57.1\%) & L $(100 \%)$ & P (98\%) & $P(100 \%)$ \\
\hline & & & & P (29.1\%) & & $H(1 \%)$ & \\
\hline & & & & $H(13.0 \%)$ & & & \\
\hline & & & & $\mathrm{R}(0.7 \%)$ & & L (1\%) & \\
\hline & & & & A (0.1\%) & & & \\
\hline & & & & I (0.1\%) & & & \\
\hline & & & & $Y(0.1 \%)$ & & & \\
\hline & 16 & $\mathrm{E}$ & G & $E(85 \%)$ & G (99\%) & $E(87 \%)$ & G (99\%) \\
\hline & & & & V (12\%) & & G (13\%) & $E(1 \%)$ \\
\hline & & & & G (3\%) & & & \\
\hline & 27 & 1 & V & V (92\%) & V (100\%) & V (100\%) & V (97\%) \\
\hline & & & & I (5\%) & & & I (1\%) \\
\hline & & & & M (3\%) & & & $\mathrm{T}(1 \%)$ \\
\hline & & & & & & & A (1\%) \\
\hline & 32 & V & I & I (83\%) & I (100\%) & I (100\%) & I (100\%) \\
\hline & & & & V (17\%) & & & \\
\hline & 37 & $\mathrm{H}$ & R & $H(100 \%)$ & $H(100 \%)$ & $H(100 \%)$ & $H(100 \%)$ \\
\hline \multirow[t]{2}{*}{ NS1 } & 74 & D & N & D (99\%) & D (100\%) & S (85\%) & D (100\%) \\
\hline & & & & & & D (14\%) & \\
\hline
\end{tabular}


Table 4 Amino acid differences between the wild-type strain ZB and the mouse-adapted strain ZB-MA (Continued)

\begin{tabular}{|c|c|c|c|c|c|c|c|}
\hline Proteins & AA site & ZB & ZB-MA & Avian H9N2 & Human H9N2 & $\mathrm{pH} 1 \mathrm{~N} 1$ & Human $\mathrm{H} 3 \mathrm{~N} 2$ \\
\hline & & & & $A(1 \%)$ & & $\mathrm{H}(1 \%)$ & \\
\hline \multirow[t]{3}{*}{ NS2 } & 75 & $E$ & V & E (99\%) & $E(100 \%)$ & $E(100 \%)$ & $E(100 \%)$ \\
\hline & & & & K (0.7\%) & & & \\
\hline & & & & $\mathrm{D}(0.3 \%)$ & & & \\
\hline
\end{tabular}

\section{${ }^{\mathrm{a}} \mathrm{H} 9$ numbering}

${ }^{\mathrm{b}} \mathrm{H} 3$ numbering is in parentheses

'The substitutions also occurred in mice-adapted influenza viruses in the previous studies

dThe substitutions which present more frequently in human influenza viruses than H9N2 AIVs was shown by bold and underline formats

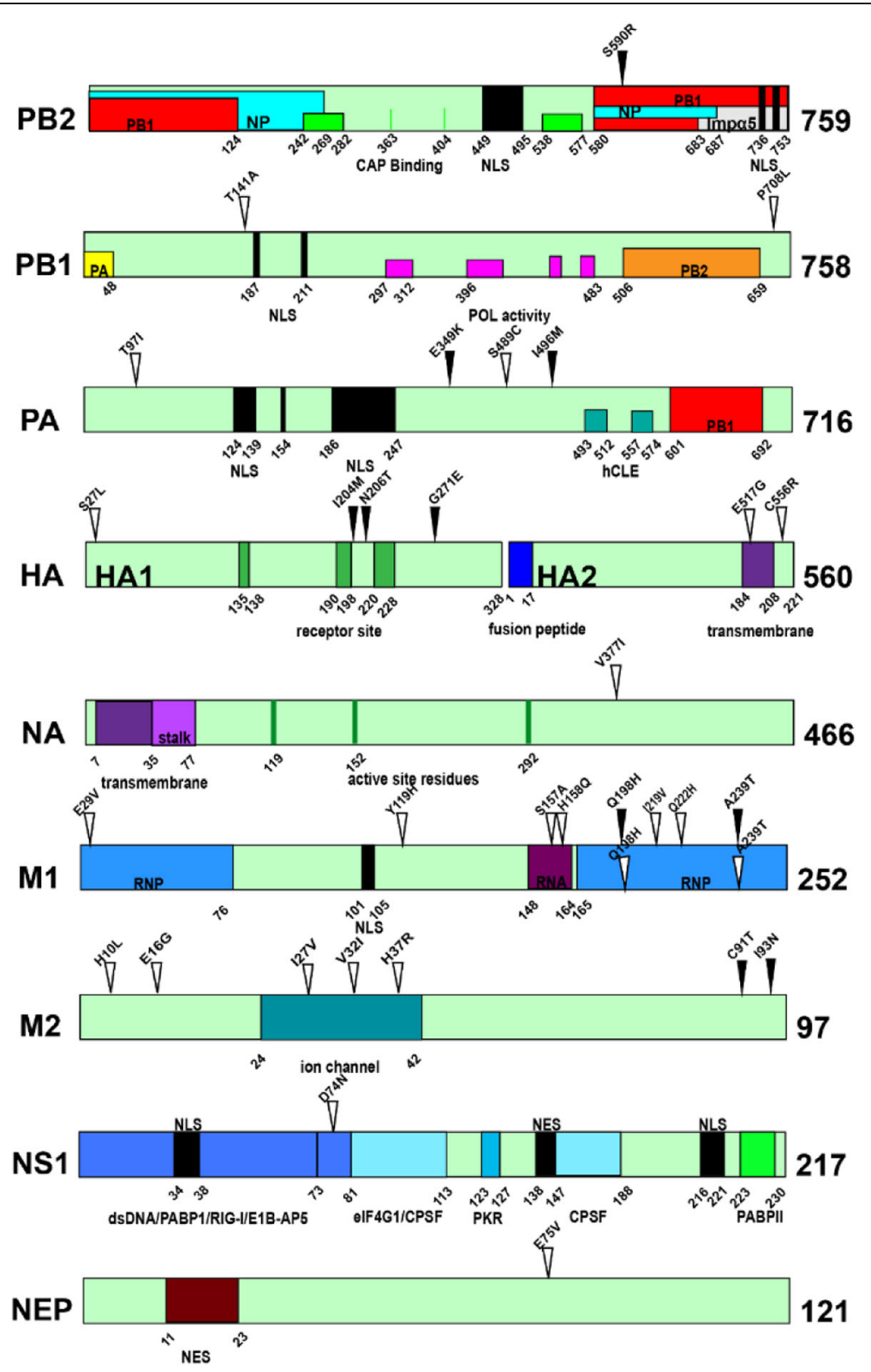

Fig. 3 Schematic diagram of influenza viral protein function. The amino acid location of mutations in G1-MA are numbered and indicated with solid triangle on the linear sequence and mutations in ZB-MA are numbered and indicated with hollow triangle. The locations of regions of protein binding, or functions, are indicated with rectangles and are labeled with respect to the interacting viral proteins 
health. Clinical studies showed that $9.7 \%$ of the children infected with $\mathrm{pH} 1 \mathrm{~N} 1 / 2009$ influenza virus developed central nervous system injury and nervous system syndrome, including hyperthermia, encephalitis, and acute necrotic encephalopathy, which increased the mortality of the patients [20]. H5N1 was isolated from the cerebrospinal fluid of a boy virus enters the CNS through the nerve pathways [21], and virus antigens and RNA can be detected the in sympathetic ganglion in mice. The ZB-MA virus becomes neurovirulent in mammals, which is not observed in the H9N2 mice-adapted strains previously and considered to be one of the main factors leading to the fatal course of infection in humans. Additionally, G1-MA might also acquire such ability after more passages. As we all know, $\mathrm{H} 5$ and $\mathrm{H} 7$ subtypes found in highly pathogenic avian influenza-infected humans have caused severe pneumonia and a very high death rate, particularly $\mathrm{H} 5 \mathrm{~N} 1$, which can cause severe disease and high mortality. This is because a low pathogenic avian influenza virus usually infects the digestive tract or respiratory tract of mammals, while the highly pathogenic ones could cause systemic infection (having been isolated from multiple organs). Highly pathogenic avian influenza viruses cause damage to cells mainly through cell necrosis or apoptosis. High levels of viral replication are associated with the extent of necrosis, which usually results in large amounts of AIVs NP proteins detected in the nuclei and cytoplasm of infected cells [22-24]. Therefore, we should pay close attention to the evolution of $\mathrm{H} 9 \mathrm{~N} 2$ virus to prevent the emergence of new influenza viruses that are a threat to public health. Collectively, our report established a theoretical framework to study the adaptation and epidemic potential of H9N2 AIVs in mammals.

\footnotetext{
Abbreviations

A: Alanine (Ala); Alv: Avian influenza virus; C: Cysteine (Cys); CNS: Central nervous system; D: Aspartic acid (Asp); dpi: days post inoculation; E: Glutamic acid (Glu); F: Phenylalanine (Phe); G: Glicine (Gly); H: Histidine (His); HA: Hemagglutinin; I: Isoleucine (lle); K: Lysine (Lys); L: Leucine (Leu); M: Matrix proteins; M: Methionine (Met); MLD $_{50}$ : $50 \%$ mouse lethal dose; N: Asparagine (Asn); NA: Neuraminidase; NP: Nucleoprotein; NS: Nonstructural protein; P: Proline (Pro); PA: Polymerase acidic protein; PB1: Polymerase basic protein 1; PB2: Polymerase basic protein 2; pfu: Plaque-forming unit; Q: Glutamine (Gln); R: Arginine (Arg); RNA: Ribonucleic acid; RNP: RNA-protein complexes; S: Serine (Ser); T: Threonine (Thr); V: Valine (Val); Y: Tyrosine (Tyr); $\mu \mathrm{L}$ : Microliter
}

\section{Acknowledgments}

Not applicable.

\section{Authors' contributions}

YPS and JHL participated in the design and supervise of the study and was involved in the manuscript editing. ZH, YRZ and ZW performed the research. JJW, QT, MYW, HLS, JP and CQL were involved in data analysis and drafting of the manuscript. All the authors have read and approved the final manuscript.

\section{Funding}

This work was supported by National Natural Science Foundation of China (31961130381 and 31430086), National Natural Science Fund for Outstanding Young Scholars (31522058), and grants from the Chang Jiang Scholars Program.

\section{Availability of data and materials}

The datasets used and/or analysed during the current study are available from the corresponding author on reasonable request.

\section{Ethics approval and consent to participate}

This study was carried out in strict accordance with the recommendations in the Guide for the Care and Use of Laboratory Animals of the Ministry of Science and Technology of the People's Republic of China. Animal experimental protocol was approved by Animal Welfare Committee of China Agricultural University (CAU) (approval numbers SKLAB-B-2010-003 for mice).

\section{Consent for publication}

Not applicable.

\section{Competing interests}

The authors declare that they have no competing interests.

\section{Author details}

${ }^{1}$ Key Laboratory of Animal Epidemiology of the Ministry of Agriculture, College of Veterinary Medicine, China Agricultural University, Beijing 100193, China. ${ }^{2}$ Beijing Huadu Yukou Poultry Industry Co. Ltd., Beijing 101206, China.

Received: 15 June 2019 Accepted: 23 September 2019

Published online: 12 November 2019

\section{References}

1. Xu KM, Smith GJD, Bahl J, et al. The genesis and evolution of H9N2 influenza viruses in poultry from southern China, 2000 to 2005. J Virol. 2007; 81(19):10389-401.

2. Panshin A, Golender N, Davidson I, et al. Variability of NS1 proteins among H9N2 avian influenza viruses isolated in Israel during 2000-2009. Virus Genes. 2010;41(3):396-405.

3. Sun $Y$, Pu J, Jiang Z, et al. Genotypic evolution and antigenic drift of H9N2 influenza viruses in China from 1994 to 2008. Vet Microbiol. 2010;146(3-4): 215-25.

4. Li XY, Shi JZ, Guo J, et al. Genetics, receptor binding property, and transmissibility in mammals of naturally isolated H9N2 Avian Influenza viruses. PLoS Pathog. 2014;10:e1004508.

5. Gao RB, Cao B, Hu YW, et al. Human infection with a novel avian-origin influenza A (H7N9) virus. N Engl J Med. 2013;368:1888-97.

6. Zhang QY, Shi JZ, Deng GH, et al. H7N9 influenza viruses are transmissible in ferrets by respiratory droplet. Science. 2013;341:410-4.

7. Shi JZ, Deng GH, Liu PH, et al. Isolation and characterization of H7N9 viruses from live poultry markets - implication of the source of current H7N9 infection in humans. Chin Sci Bull. 2013;58(16):1857-63.

8. Liang L, Jiang L, Li JP, et al. Low Polymerase Activity Attributed to PA Drives the Acquisition of the PB2 E627K Mutation of H7N9 Avian Influenza Virus in Mammals. MBio. 2019;10(3):e01162-19.

9. Lam T, Wang J, Shen $Y$, et al. The genesis and source of the H7N9 influenza viruses causing human infections in China. Nature. 2013;502(7470): $241-4$.

10. Liu D, Shi W, Shi Y, et al. Origin and diversity of novel avian influenza a H7N9 viruses causing human infection: phylogenetic, structural, and coalescent analyses. Lancet. 2013;381(9881):1926-32.

11. Peiris $M$, Yuen $K Y$, Leung $C W$, et al. Human infection with influenza H9N2. Lancet (North American Edition). 1999;354(9182):0-917.

12. Wu $\mathrm{R}$, Zhang $H$, Yang $\mathrm{K}$, et al. Multiple amino acid substitutions are involved in the adaptation of H9N2 avian influenza virus to mice. Vet Microbiol. 2009; 138(1-2):85-91.

13. Ping J, Dankar SK, Forbes NE, et al. PB2 and Hemagglutinin mutations are major determinants of host range and virulence in mouse-adapted influenza a virus. J Virol. 2010;84(20):10606-18.

14. Jingjing W, Yipeng S, Qi X, et al. Mouse-Adapted H9N2 Influenza A Virus PB2 Protein M147L and E627K Mutations Are Critical for High Virulence. PLoS One. 2012;7(7):e40752. 
15. Chen $H$, Bright RA, Subbarao $K$, et al. Polygenic virulence factors involved in pathogenesis of 1997 Hong Kong H5N1 influenza viruses in mice. Virus Res. 2007;128(1-2):0-163.

16. Qin J, Peng O, Shen $\mathrm{X}$, et al. Multiple amino acid substitutions involved in the adaption of three avian-origin H7N9 influenza viruses in mice. Virol $\mathrm{J}$. 2019;16(1):3.

17. Kamiki H, Matsugo H, Kobayashi T, et al. A PB1-K577E Mutation in H9N2 Influenza Virus Increases Polymerase Activity and Pathogenicity in Mice. Viruses. 2018;10:653.

18. Zhang Z, Hu S, Li Z, et al. Multiple amino acid substitutions involved in enhanced pathogenicity of LPAI H9N2 in mice. Infect Genet Evol. 2011;11(7): 1790-7.

19. Mizuguchi M. Acute encephalopathy associated with influenza and other viral infections. Acta Neurol Scand. 2007;115:45-56.

20. Wilking AN, Elliott E, Garcia MN, et al. Central nervous system manifestations in pediatric patients with influenza a H1N1 infection during the 2009 pandemic. Pediatr Neurol. 2014;51(3):370-6.

21. De Jong MD, Cam BV, Qui PT, et al. Fatal avian influenza a (H5N1) in a child presenting with diarrhea followed by coma. N Engl J Med. 2005; 352(7):686-91

22. Reperant $L A$, Rimmelzwaan $G F$, Kuiken $T$. Avian influenza viruses in mammals. Rev Sci Tech. 2009:28(1):137-59.

23. Hooper P. Pathology of low and high virulent influenza virus infections. Avian Dis. 2003:47:134-41.

24. Perkins LEL, Swayne DE. Comparative susceptibility of selected avian and mammalian species to a Hong Kong-origin $\mathrm{H} 5 \mathrm{~N} 1$ high-pathogenicity avian influenza virus. Avian Dis. 2003;47(s3):956-67.

\section{Publisher's Note}

Springer Nature remains neutral with regard to jurisdictional claims in published maps and institutional affiliations.

Ready to submit your research? Choose BMC and benefit from:

- fast, convenient online submission

- thorough peer review by experienced researchers in your field

- rapid publication on acceptance

- support for research data, including large and complex data types

- gold Open Access which fosters wider collaboration and increased citations

- maximum visibility for your research: over $100 \mathrm{M}$ website views per year

At BMC, research is always in progress.

Learn more biomedcentral.com/submissions 